\title{
A Rare Case of a Large, Deceitfully Quiet Brainstem Arteriovenous Malformation Presenting Only as Dizziness
}

\author{
Swathi Rao ${ }^{1}$, Fanny Giron ${ }^{1}$ \\ 1. Internal Medicine, MacNeal Hospital, Berwyn, USA
}

Corresponding author: Swathi Rao, swathi.rao@lumc.edu

\begin{abstract}
Dizziness is one of the most frequent complaints encountered in the medical practice affecting $15 \%-20 \%$ of adults yearly, and can be challenging to assess. Most patients use dizziness as a non-specific term, and thus suffer prejudice from the physicians' end and can be disregarded frequently. Dizziness can be a symptom of various diseases, some with sinister pathologies. We present a case of garden-variety vertigo that unfurled to be not-so-simple, emphasizing the importance of a thorough history and physical examination again even in the era of technology. A 32-year-old male patient with no past medical history presented with dizziness, later clarified as gradually progressive vertigo for two years, with unstable gait, dysarthria, and occasional diplopia. Physical examination found sustained nystagmus that changed direction with horizontal gaze, vertical nystagmus with upward gaze, dysarthria, and a wide-based ataxic gait. CT head without contrast revealed indeterminate hypodense areas in the left midbrain, pons, and cerebellar hemisphere. MRI brain identified a 2.8 × 3.4 × $4.2 \mathrm{~cm}$ Spetzler-Martin grade IV brainstem arteriovenous malformation (AVM) involving the left midbrain, pons, and cerebellum. Feeders were mostly from the posterior circulation, with three intranidal aneurysms, all draining into the deep venous system. The AVM was deemed inoperable, and the patient was treated with onyx embolization for two/three feeding vessel aneurysms. After treatment, the symptoms persisted, and the patient was diagnosed with major depressive disorder (MDD) six months after diagnosis, and was admitted a year later with suicidal ideation and substance use disorder. Brain AVMs are rare clinical entities that present in $0.1 \%$ of the population, mostly presenting as intracranial bleeds. When they do rarely present with isolated focal neurologic deficits, it has been attributed to a vascular steal phenomenon, hemorrhage, or a mass effect. The isolated findings of vertigo and dysarthria are highly nonspecific; with such presentation, clinicians should consider etiologies under the realm of vertigo of central origin. An untreatable AVM reduces patients' quality of life and has been linked to depression and anxiety, and thus patients may benefit from psychosocial therapy. Although preventing intracranial hemorrhage (ICH) is the primary concern with brain AVMs, the rest of the patient's profile should not be forgotten.
\end{abstract}

Received 06/08/2020

Review began $06 / 23 / 2020$ Review ended 06/24/2020 Published 06/27/2020

\section{() Copyright 2020}

Rao et al. This is an open access article distributed under the terms of the Creative Commons Attribution License CC-BY 4.0., which permits unrestricted use, distribution, and reproduction in any medium, provided the original author and source are credited.
Categories: Cardiac/Thoracic/Vascular Surgery, Neurology, Radiology Keywords: arteriovenous malformation, dizziness, nystagmus, vertigo

\section{Introduction}

Dizziness is one of the most frequent complaints encountered in the medical practice affecting $15 \%-20 \%$ of adults yearly, and it can be a challenging symptom to assess [1]. Both history and physical exam are key components to ascertain the etiology of the patient's dizziness. Nearly $40 \%$ of patients complaining of dizziness are found to have peripheral vertigo, and $10 \%$ are found to have vertigo of central origin $[2,3]$. Vertigo is a subtype of dizziness defined as an illusory sensation of movement. Reaching the correct diagnosis can become puzzling for physicians because it encompasses a wide range of diagnosis starting from a benign condition to a life-threatening disease.

Peripheral vertigo is usually characterized by imbalance, nausea, vomiting, and nystagmus that can be horizontal or mixed; the presence of ear symptoms makes this diagnosis more likely. Conversely, central vertigo is associated with severe imbalance to the point where sometimes patients are unable to walk, additional neurologic manifestations may also be present, nausea and vomiting are not as pronounced, and nystagmus is typically pure vertical or torsional [4]. Here we present a singular case of vertigo, proving how important it is to have a high clinical suspicion when a patient with this symptom walks in.

\section{Case Presentation}

We present a rare case of an infratentorial brainstem arteriovenous malformation (AVM). A 32-year-old male patient with no other past medical history presented with dizziness which was further clarified as gradually progressive vertigo for two years, leading to unstable gait, mild dysarthria, and occasional diplopia. The symptoms were not associated with headache, nausea, vomiting, tinnitus, or hearing loss. There was no history of muscle weakness, seizures, or loss of consciousness. On thorough clinical examination, he was found to have a sustained nystagmus that changed direction with horizontal gaze and vertical nystagmus with upward gaze. He had dysarthria, a wide-based ataxic gait. A single large or multiple 


\section{Cureus}

lesions affecting pons, midbrain, and cerebellum were suspected. Initial plain CT head (Figure 1) in emergency room revealed an indeterminate hypodense area in the left midbrain, pons, and cerebellar hemisphere.

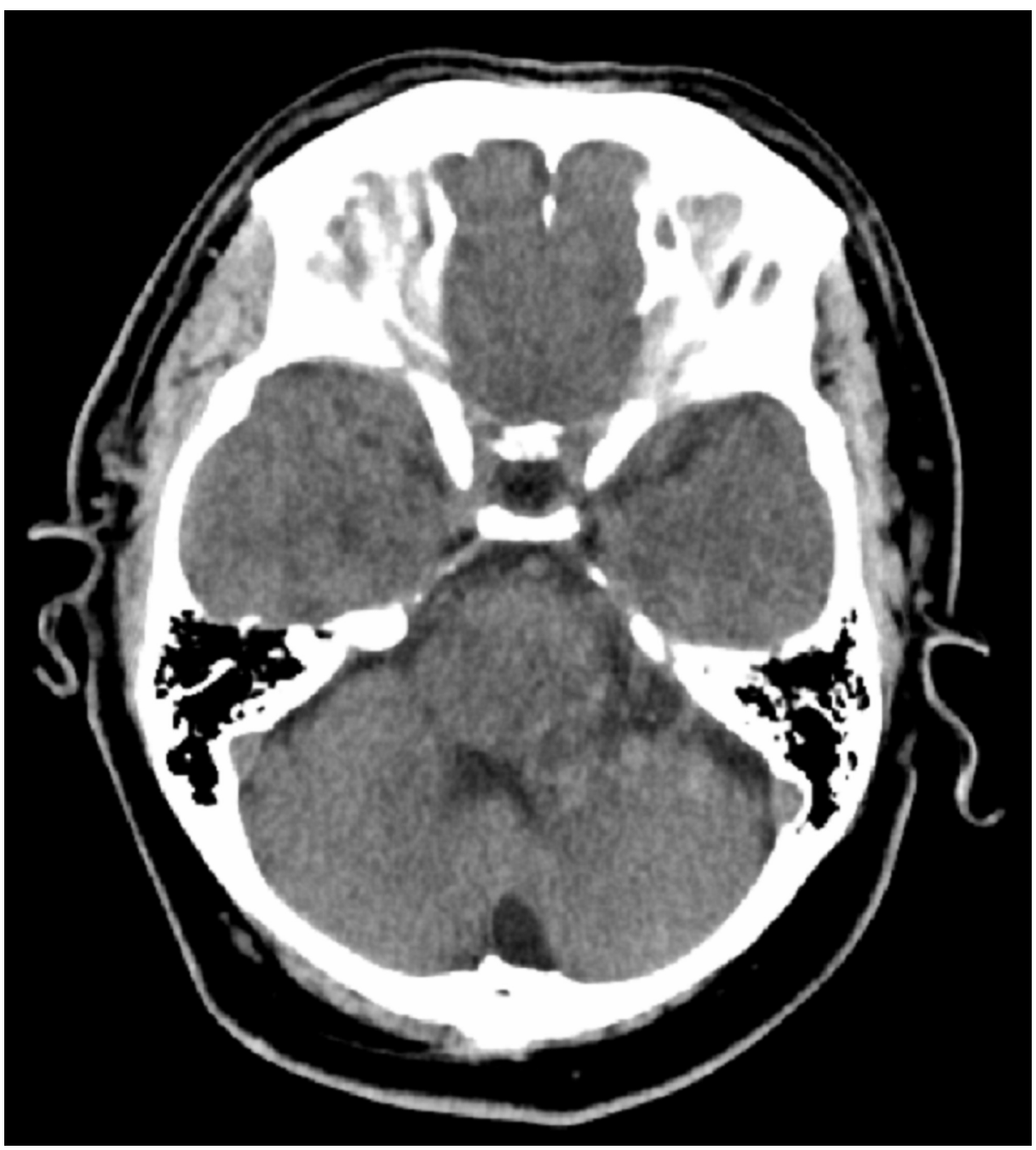

FIGURE 1: CT head without contrast, axial section

MRI brain (Figures 2-4) identified Spetzler-Martin grade IV brainstem AVM measuring approximately $2.8 \mathrm{x}$ $3.4 \times 4.2 \mathrm{~cm}$ primarily involving the left paracentral brainstem (midbrain, pons, and cerebellum). 


\section{Cureus}

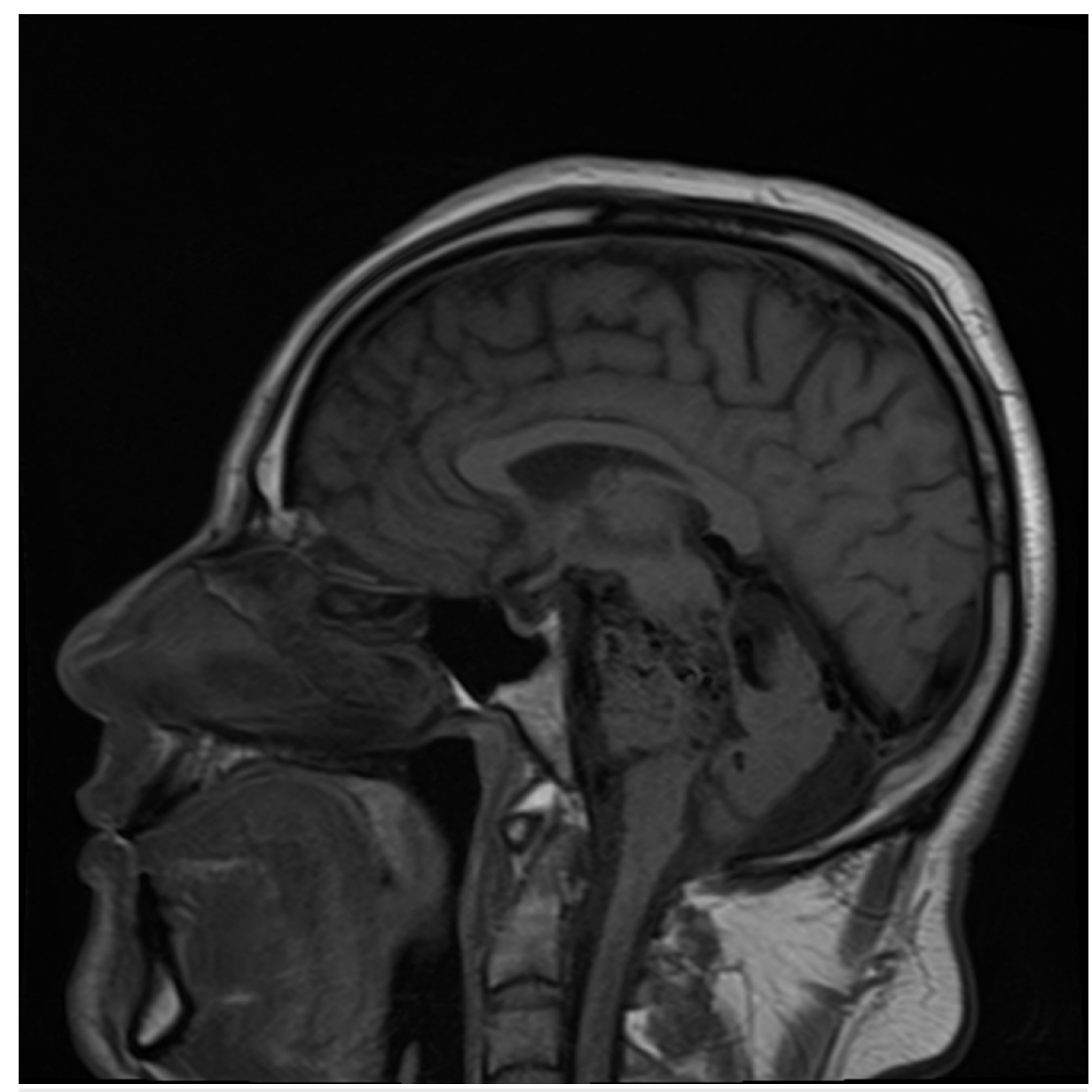

FIGURE 2: MRI head without contrast, sagittal section 


\section{Cureus}

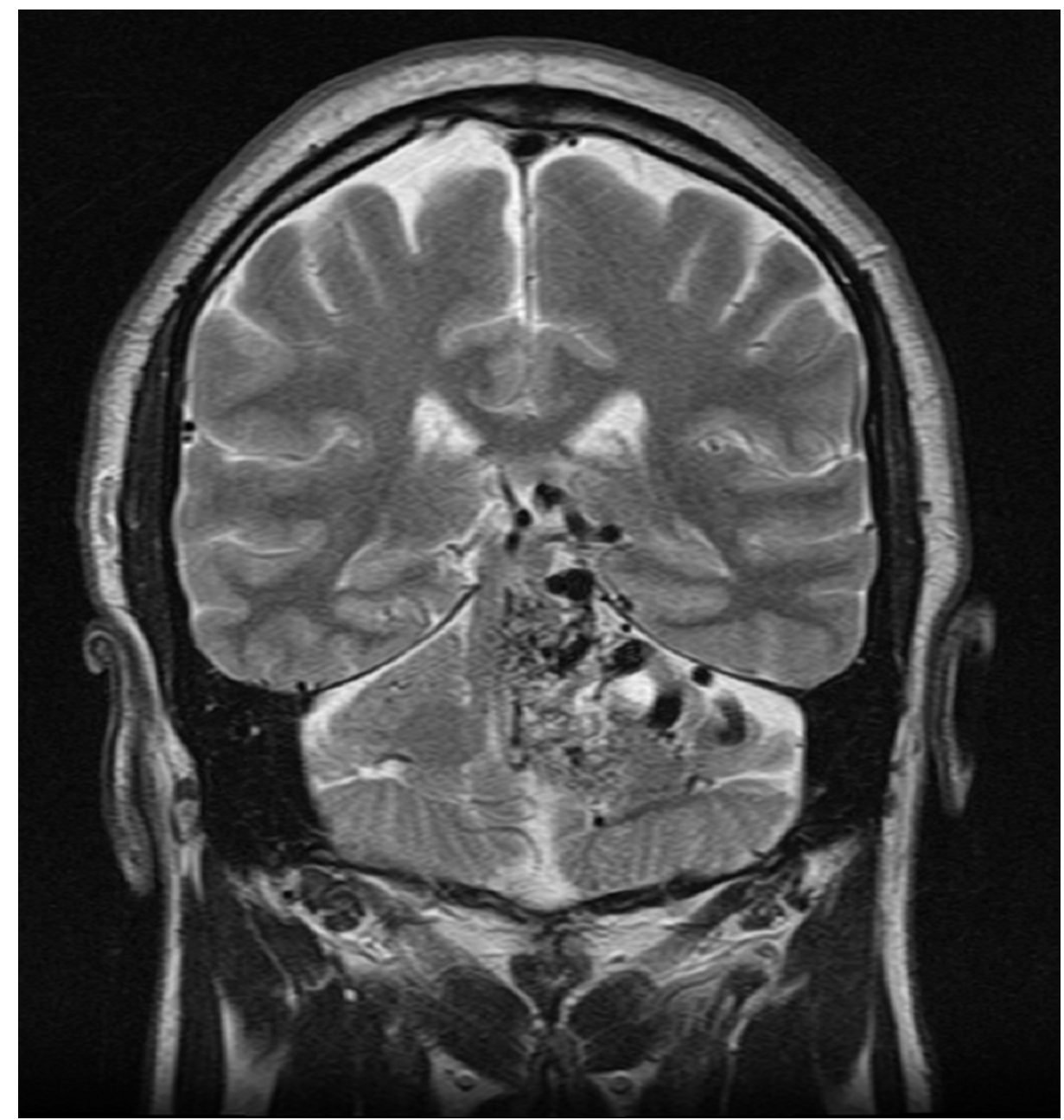

FIGURE 3: MRI head without contrast, coronal section 


\section{Cureus}

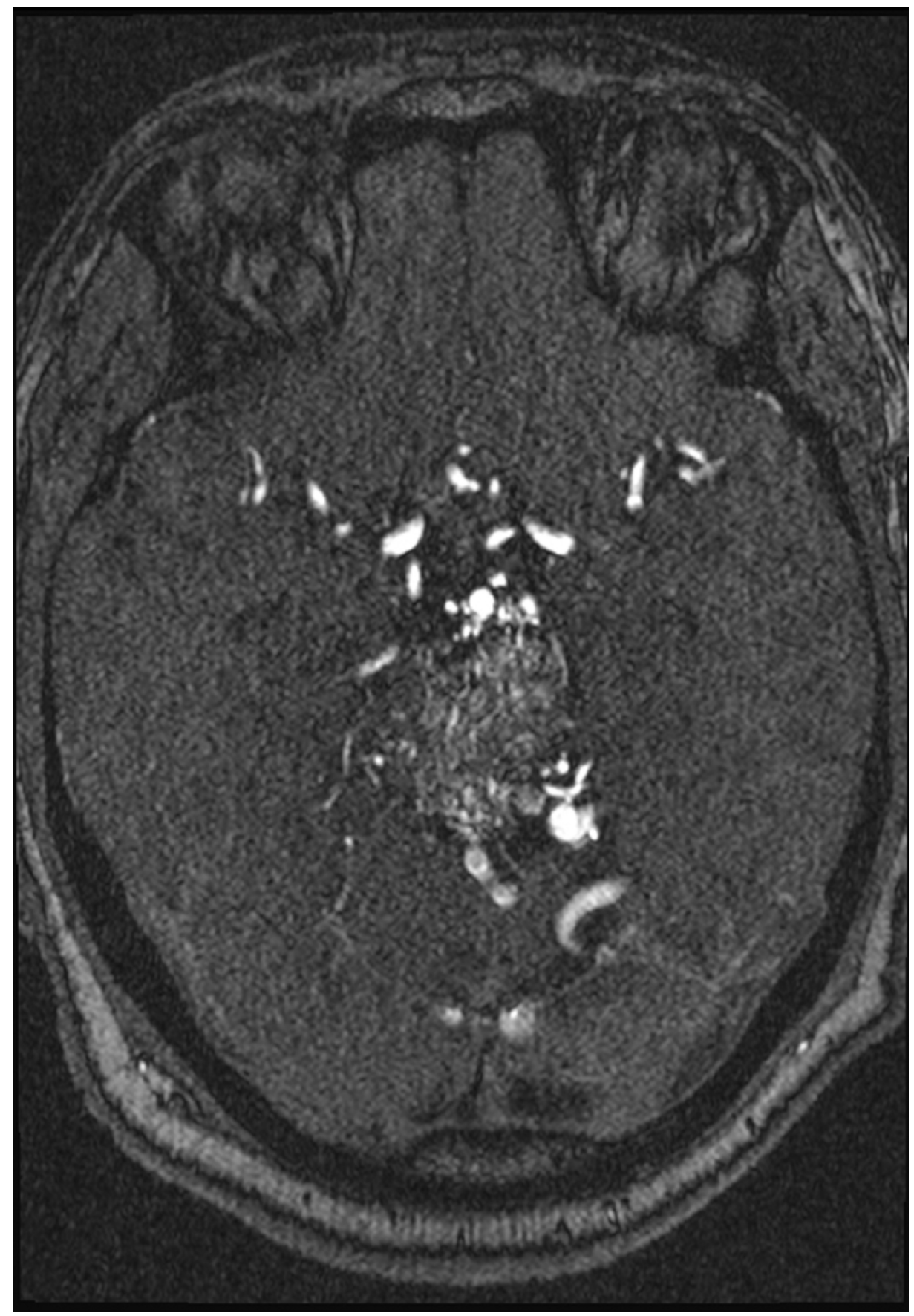

FIGURE 4: MRI head with contrast, axial section

Feeders were mostly from the posterior circulation, with three intranidal aneurysms, all draining into the deep venous system (Figures 5-7). The AVM was deemed inoperable, and the patient was treated with onyx embolization for two of the three feeding vessel aneurysms. Even following the treatment, the symptoms persisted, affecting the patient's quality of life significantly. He was diagnosed with major depressive disorder (MDD) six months after the diagnosis and treatment and was admitted a year later with suicidal ideation and substance use disorder. 


\section{Cureus}

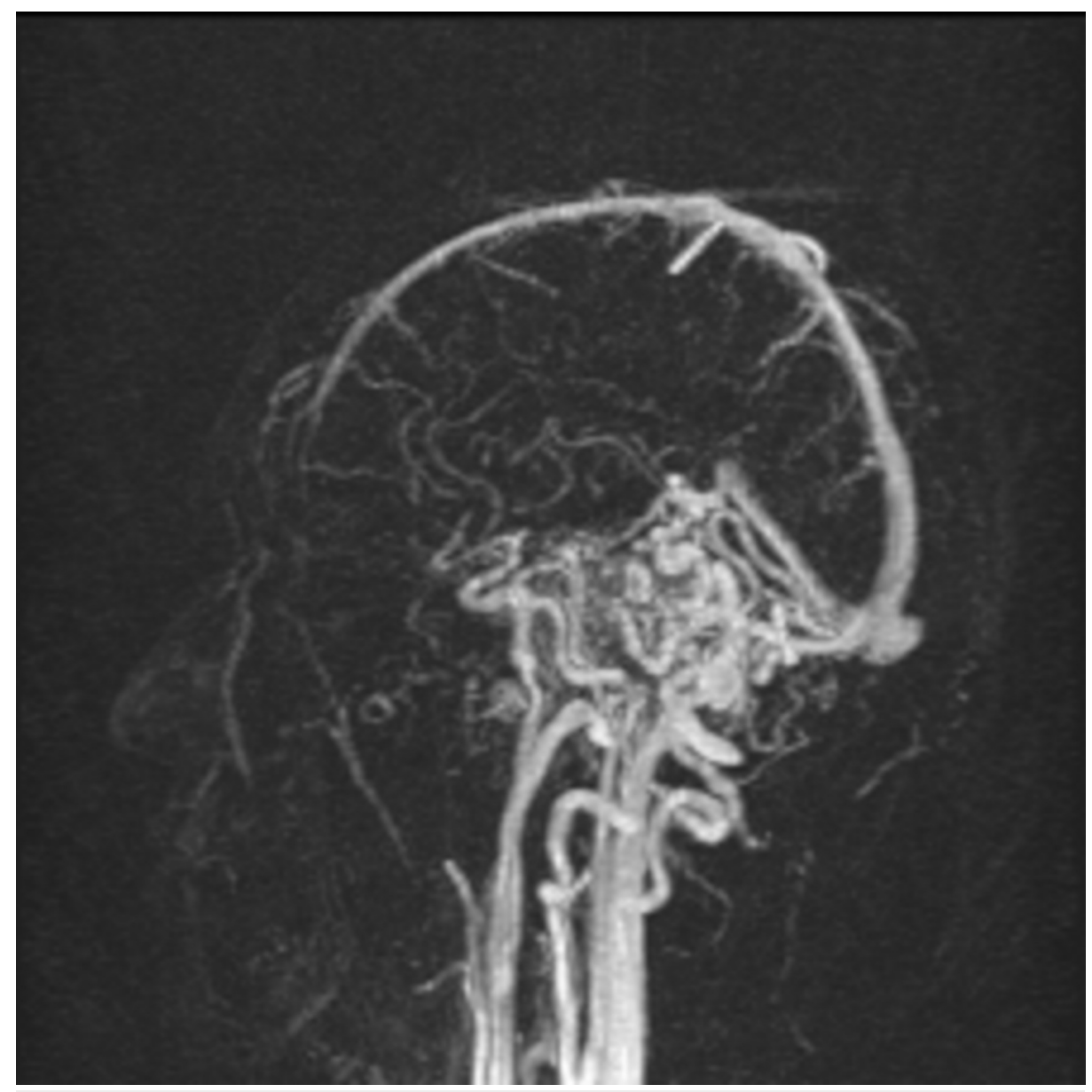

FIGURE 5: MRA head with contrast, sagittal section 


\section{Cureus}

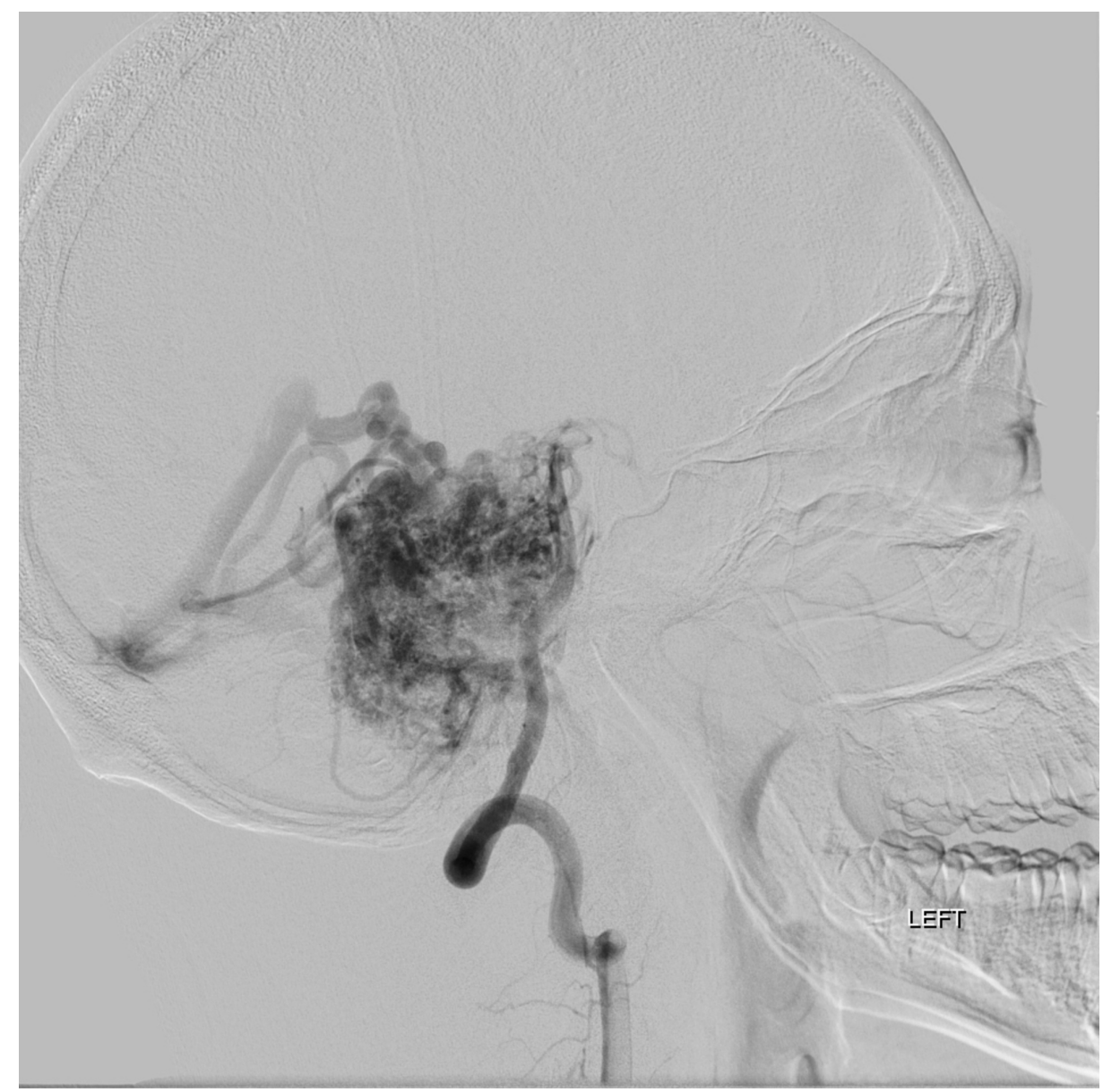

FIGURE 6: Angiography of vertebral artery, sagittal section 


\section{Cureus}

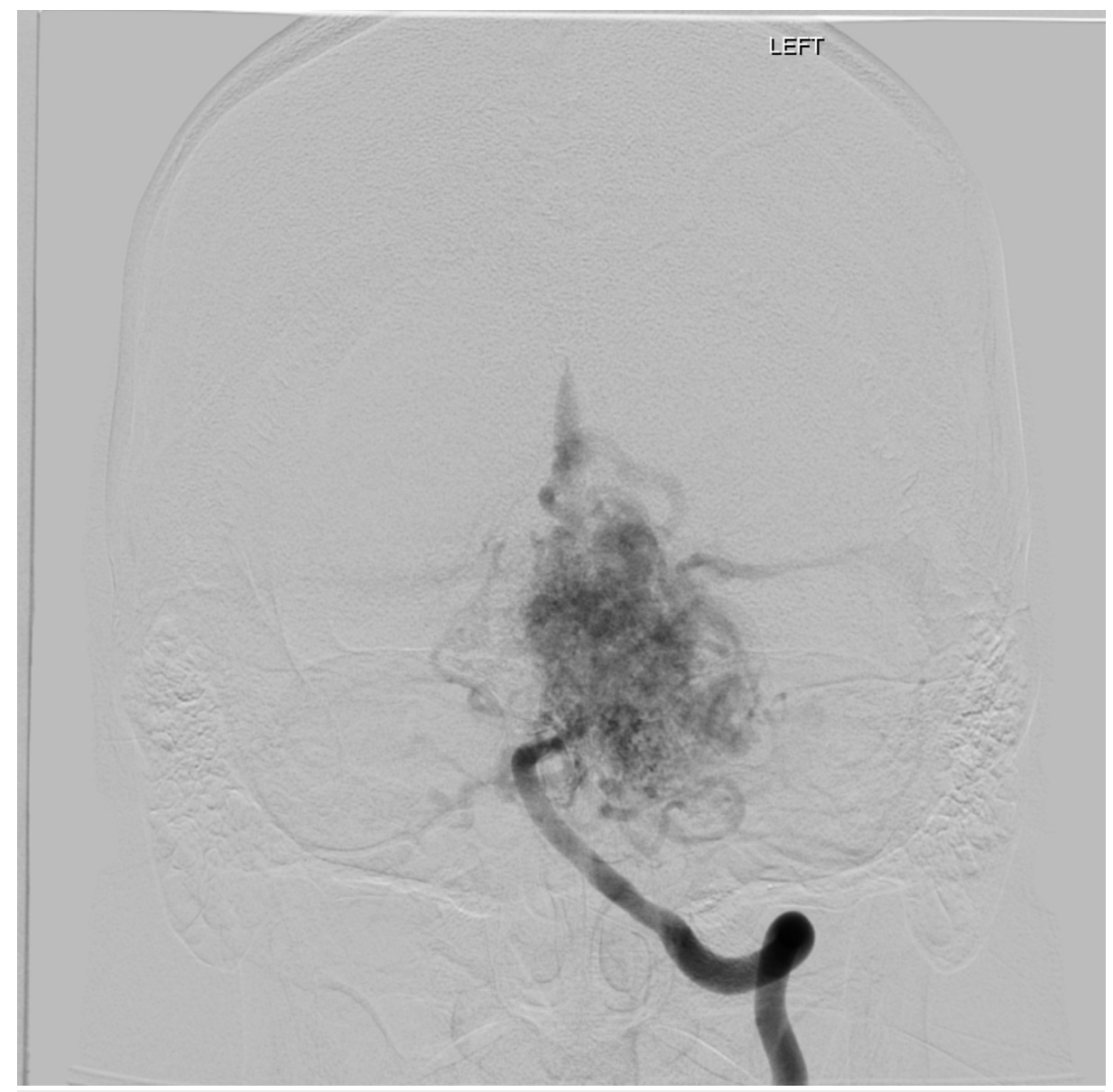

\section{FIGURE 7: Angiography of vertebral artery, coronal section}

\section{Discussion}

This case is a rare vascular malformation presenting in an unusual location and manifestation. AVMs in the brain are rare clinical entities that present in only $0.1 \%$ of the population [5]. Of all the congenital vascular malformations, they are the most dangerous, commonly presenting with intracranial hemorrhage (ICH) $(41 \%-79 \%)$ or seizure $(11 \%-33 \%)[6-8]$. Some also present with headache. When they do rarely present with isolated focal neurologic deficits, it has been attributed to a vascular steal phenomenon, hemorrhage, or a mass effect [9]. Ninety percent of AVMs are supratentorial, while the remaining occur in the posterior fossa. They are usually single and considered sporadic. Multiple lesions point to a familial disorder like hereditary hemorrhagic telangiectasia (HHT) $[10,11]$. Their size can vary widely, and they sometimes undergo growth or regression over time. They are angiographically seen as direct connections between arteries and veins without an intervening capillary bed and can have multiple feeder vessels. About 20\%-25\% develop aneurysms of the vessels, increasing the chances of an intracranial bleed [12]. Surprisingly, the size of the AVM does not seem to affect the risk of hemorrhage.

This patient presented with a posterior fossa AVM. This localization accounts for $7 \%-15 \%$ of all intracranial AVMs, the most common presentation for these types of AVMs are infratentorial hemorrhages (60\%-86\%) followed by progressive neurologic deficits and less commonly cranial nerve palsies or ataxia [13]. The isolated findings of vertigo and dysarthria without hemorrhage or seizures are highly non-specific and have a multitude of differential diagnoses; with such presentation clinicians should consider etiologies under the realm of vertigo of central origin. While approaching to vertigo, thorough history focused on duration and onset of the vertigo, and physical examination focusing on focal neurologic deficits particularly eye movements, nystagmus, cranial nerves, and cerebellar exam will help us narrow down the etiologies and identify the patients who require imaging studies. Some of the differentials considered in this case were multiple sclerosis, Wernicke's encephalopathy, tumor or metastatic disease, and spinocerebellar ataxia. The realization of the presence of an untreatable AVM reduces the patient's quality of life, and this finding has been linked to depression and anxiety [14-16]. It can be beneficial to refer patients to psychiatrists or therapists at the time of diagnosis or even after treatment to provide them support and assist them to build coping skills. Although preventing ICH is the primary concern with brain AVMs, rest of the patient's profile should not be set aside. 


\section{Conclusions}

While approaching vertigo, a thorough history focused on duration and onset of the vertigo, and physical examination focusing on focal neurologic deficits, eye movements, nystagmus, cranial nerves, and cerebellar exam is pivotal. An untreatable AVM reduces patients' quality of life and has been linked to depression and anxiety, and thus patients may benefit from psychosocial therapy. Although preventing ICH is the primary concern with brain AVMs, the rest of the patient's profile should not be forgotten.

\section{Additional Information \\ Disclosures}

Human subjects: Consent was obtained by all participants in this study. Conflicts of interest: In compliance with the ICMJE uniform disclosure form, all authors declare the following: Payment/services info: All authors have declared that no financial support was received from any organization for the submitted work. Financial relationships: All authors have declared that they have no financial relationships at present or within the previous three years with any organizations that might have an interest in the submitted work. Other relationships: All authors have declared that there are no other relationships or activities that could appear to have influenced the submitted work.

\section{References}

1. Neuhauser HK, Radtke A, von Brevern M, Lezius F, Feldmann M, Lempert T: Burden of dizziness and vertigo in the community. Arch Intern Med. 2008, 168:2118-2124. 10.1001/archinte.168.19.2118

2. Kroenke K, Lucas CA, Rosenberg ML, Scherokman B, Herbers JE Jr, Wehrle PA, Boggi JO: Causes of persistent dizziness: a prospective study of 100 patients in ambulatory care. Ann Intern Med. 1992, 117:898904. 10.7326/0003-4819-117-11-898

3. Karatas M: Central vertigo and dizziness: epidemiology, differential diagnosis, and common causes . Neurologist. 2008, 14:355-364. 10.1097/NRL.0b013e31817533a3

4. Mohr JP, Kejda-Scharler J, Pile-Spellman J: Diagnosis and treatment of arteriovenous malformations . Curr Neurol Neurosci Rep. 2013, 13:324. 10.1007/s11910-012-0324-1

5. Fullerton HJ, Achrol AS, Johnston SC, et al.: Long-term hemorrhage risk in children versus adults with brain arteriovenous malformations. Stroke. 2005, 36:2099-2104. 10.1161/01.STR.0000181746.77149.2b

6. Garcin B, Houdart E, Porcher R, Manchon E, Saint-Maurice JP, Bresson D, Stapf C: Epileptic seizures at initial presentation in patients with brain arteriovenous malformation. Neurology. 2012, 78:626-631. 10.1212/WNL.0b013e3182494d40

7. Al-Shahi Salman R: The outlook for adults with epileptic seizure(s) associated with cerebral cavernous malformations or arteriovenous malformations. Epilepsia. 2012, 53:34-42. 10.1111/j.15281167.2012.03611.x

8. Moftakhar P, Hauptman JS, Malkasian D, Martin NA: Cerebral arteriovenous malformations. Part 2: physiology. Neurosurg Focus. 2009, 26:11. 10.3171/2009.2.FOCUS09317

9. Willinsky RA, Lasjaunias P, Terbrugge K, Burrows P: Multiple cerebral arteriovenous malformations (AVMs). Review of our experience from 203 patients with cerebral vascular lesions. Neuroradiology. 1990, 32:207210. 10.1007/BF00589113

10. Bharatha A, Faughnan ME, Kim H, et al.: Brain arteriovenous malformation multiplicity predicts the diagnosis of hereditary hemorrhagic telangiectasia: quantitative assessment. Stroke. 2012, 43:72-78. 10.1161/STROKEAHA.111.629865

11. Perata HJ, Tomsick TA, Tew JM Jr: Feeding artery pedicle aneurysms: association with parenchymal hemorrhage and arteriovenous malformation in the brain. J Neurosurg. 1994, 80:631-634. 10.3171/jns.1994.80.4.0631

12. Almeida JP, Medina R, Tamargo RJ: Management of posterior fossa arteriovenous malformations. Surg Neurol Int. 2015, 6:31. 10.4103/2152-7806.152140

13. Li Y, Dai W, Zhang J: Anxiety, depression and quality of life in patients with a treated or untreated unruptured intracranial aneurysm. J Clin Neurosci. 2017, 45:223-226. 10.1016/j.jocn.2017.07.019

14. Garzon-Muvdi T, Yang W, Luksik AS, Ruiz-Valls A, Tamargo RJ, Caplan J, Tamargo RJ: Postoperative delayed paradoxical depression after uncomplicated unruptured intracranial aneurysm surgery. World Neurosurg. 2017, 99:63-69. 10.1016/j.wneu.2016.11.101

15. Solheim O, Eloqayli H, Muller TB, Unsgaard G: Quality of life after treatment for incidental, unruptured intracranial aneurysms. Acta Neurochir. 2006, 148:821-830. 10.1007/s00701-006-0804-7

16. Brilstra EH, Rinkel GJ, van der graaf Y, Sluzewski M, Groen RJ, Lo RTH, Tulleken CAF: Quality of life after treatment of unruptured intracranial aneurysms by neurosurgical clipping or by embolisation with coils. A prospective, observational study. Cerebrovasc Dis. 2004, 17:44-52. 10.1159/000073897 